\title{
Fabrication of a Scaled MgB2 Racetrack Demonstrator Pole for a 10-MW Direct-Drive Wind Turbine Generator
}

Magnusson, Niklas; Eliassen, Jan Christian; Abrahamsen, Asger Bech; Helleso, Svein Magne; Runde, Magne; Nysveen, Arne; Moslatt, Lars-Erik; Bjerkli, Jarle; King, Patrick

Published in:

I E E E Transactions on Applied Superconductivity

Link to article, DOI:

10.1109/TASC.2018.2815027

Publication date:

2018

Document Version

Peer reviewed version

Link back to DTU Orbit

Citation (APA):

Magnusson, N., Eliassen, J. C., Abrahamsen, A. B., Helleso, S. M., Runde, M., Nysveen, A., Moslatt, L-E., Bjerkli, J., \& King, P. (2018). Fabrication of a Scaled MgB2 Racetrack Demonstrator Pole for a 10-MW DirectDrive Wind Turbine Generator. I E E E Transactions on Applied Superconductivity, 28(4), [5207105]. https://doi.org/10.1109/TASC.2018.2815027

\section{General rights}

Copyright and moral rights for the publications made accessible in the public portal are retained by the authors and/or other copyright owners and it is a condition of accessing publications that users recognise and abide by the legal requirements associated with these rights.

- Users may download and print one copy of any publication from the public portal for the purpose of private study or research.

- You may not further distribute the material or use it for any profit-making activity or commercial gain

- You may freely distribute the URL identifying the publication in the public portal 


\title{
Fabrication of a Scaled $\mathrm{MgB}_{2}$ Racetrack Demonstrator Pole for a 10 MW Direct Drive Wind Turbine Generator
}

\author{
N. Magnusson, J. C. Eliassen, A. B. Abrahamsen, S. M. Hellesø, M. Runde, A. Nysveen, L. E. Moslått, J. Bjerkli \\ and P. King
}

\begin{abstract}
Field windings made of $\mathrm{MgB}_{2}$ wires or tapes are considered for their potential to reduce volume, weight and cost of large offshore wind turbine generators. To gain experience of how to use this relatively new material in full-scale generators, tests of different winding methodologies and techniques are needed. In this paper, we describe in detail the steps used to wind a racetrack coil with a length of $1 \mathrm{~m}$ and a width of $0.5 \mathrm{~m}$ out of $4.5 \mathrm{~km}$ of $\mathrm{MgB}_{2}$ superconducting tape. The width corresponds to a full-scale pole of a $10 \mathrm{MW}$ generator, whereas the length of the straight section is shorter than the corresponding full-scale pole. The coil was built up of $\mathbf{1 0}$ double pancake coils. Each double pancake coil was wet-wound using a semi-automatic winding process, where Stycast 2850 was applied directly to the $\mathrm{MgB}_{2}$ tape without any other dedicated electrical insulation. The strengths and weaknesses of the winding process are discussed and compared to the dry-winding method.
\end{abstract}

Index Terms-Coil winding, generators, magnesiumdiboride, superconductivity, wind turbine.

\section{INTRODUCTION}

$\mathrm{O}^{\prime}$ FFSHORE wind turbines are offered with increasing power ratings to reduce the installation cost of the foundations per unit power. Power ratings of $10 \mathrm{MW}$ and beyond are in this context discussed. For the preferred direct drive solution (avoiding a gearbox), conventional generators then become large and heavy. To overcome this problem, superconductors are considered in the field winding of the generator for their ability to carry high current densities, which can lead to reduced volume, weight, and ultimately cost of the generator and of the wind turbine as a whole.

There are different conductor options for superconducting generators. Based on the technology for MRI-apparatuses, $\mathrm{NbTi}$ conductors used at $4 \mathrm{~K}$ are suggested for the generator field winding with the main advantage that the core superconductor technology already exists [1]. The high-

Manuscript received September 14, 2017. This work has been done as part of the INNWIND.EU project funded by the European Community's Seventh Framework Programme under grant agreement No. 308974 (INNWIND.EU) and the NOWITECH programme funded by the Research Council of Norway under contract No.193823.

N. Magnusson, M. Runde, S. M. Helles $\emptyset$, J. Bjerkli and P. King are with SINTEF Energy Research, NO-7465 Trondheim, Norway (phone: +47 90718577; e-mail: niklas.magnusson@sintef.no.

J. C. Eliassen, A. Nysveen and L. E. Moslått are with the Department of Electric Power Engineering, Norwegian University of Science and Technology, NO-7491 Trondheim, Norway; e-mail: arne.nysveen@ntnu.no.

A. B. Abrahamsen is with DTU Wind Energy, DK-4000 Roskilde, Denmark; email: asab@dtu.dk. temperature $\mathrm{YBCO}$ conductors can be used for field windings in the 30-40 $\mathrm{K}$ range [2], [3] with a less expensive cooling system. In the intermediate temperature range of $10-20 \mathrm{~K}$, the $\mathrm{MgB}_{2}$ conductor is a viable option, with lower cooling cost than NbTi conductors and lower conductor cost than YBCO conductors [4], [5].

Several design studies have recently been performed for $10 \mathrm{MW}$-class HTS and $\mathrm{MgB}_{2}$ based wind turbine generators. In [6] air core and iron core topologies are compared, whereas double-layer lap and concentrated copper armature windings are compared for use with HTS field windings in [7]. A comparison between copper, permanent magnet and HTS based field windings is given in [8]. A fully superconducting generator, with HTS field windings and $\mathrm{MgB}_{2}$ armature windings, is discussed in [9], whereas an $\mathrm{MgB}_{2}$ based field winding generator design is presented in [10].

To realize optimized $\mathrm{MgB}_{2}$ coils for wind power turbines, several issues need to be considered. Among them are the winding methodology and the practical steps of the actual winding process.

Large round $\mathrm{MgB}_{2}$ coils have been presented for MRI [11], [12] and induction heater [13] applications, in addition to several smaller test coils [14]-[18]. In the wind turbine generator, racetrack shaped coils are employed. Such coils are described in [19], where the coils were wound dry and then vacuum impregnated with epoxy in a second step. The other impregnation option is wet winding, where epoxy is applied to the wire during winding.

In this work, we describe in detail the different steps in the fabrication of a $5 \mathrm{H}$ wet-wound coil, including the winding of ten double pancake sub-coils, the assembly of the double pancakes, and the design and mounting of the mechanical support.

\section{COIL DESIGN}

\section{A. Superconductor}

The conductor, produced by Columbus Superconductors, consisted of $19 \mathrm{MgB}_{2}$ filaments embedded in a nickel matrix with a copper strip soldered to one side. The dimensions of the conductor were $0.5 \mathrm{~mm} \times 3 \mathrm{~mm}$, and of the copper strip $0.2 \mathrm{~mm} \times 3 \mathrm{~mm}$. The critical current, measured by the producer, was approximately $235 \mathrm{~A}$ at $20 \mathrm{~K}$ and $1.8 \mathrm{~T}, 370 \mathrm{~A}$ at $16 \mathrm{~K}$ and $1.8 \mathrm{~T}$, and $545 \mathrm{~A}$ at $10 \mathrm{~K}$ and $1.8 \mathrm{~T}$, with a small variation between the received pieces. 


\section{B. Coil Parameters}

The coil design takes the starting point in one of 32 poles of a $10 \mathrm{MW}$ wind turbine generator design with a torque of 10.6 $\mathrm{MNm}$, rotational speed of $9.7 \mathrm{rpm}$, frequency of $2.6 \mathrm{~Hz}$ [20]. To fit the pole into an existing cryostat (allowing a total length of $1.1 \mathrm{~m}$ ) and to reduce the amount of conductor, the straight section was made shorter than the $3.1 \mathrm{~m}$ full-scale pole, while keeping the number of turns, the pole cross-section and the end section dimensions. The coil was dimensioned for a current of $225 \mathrm{~A}$ (to be obtained at $12 \mathrm{~K}$ ), which corresponds to a maximum magnetic field of $2.8 \mathrm{~T}$ appearing at the inside of the end section. The main coil parameters are summarized in Table I.

TABLE I

COIL PARAMETERS

\begin{tabular}{ll}
\hline \hline & \\
Quantity & Value \\
\hline Straight section, length & $500 \mathrm{~mm}$ \\
End section, inner diameter & $300 \mathrm{~mm}$ \\
Coil height & $81 \mathrm{~mm}$ \\
Coil width, straight section $^{*}$ & $87 \mathrm{~mm}$ \\
Coil width, end section $^{*}$ & $81 \mathrm{~mm}$ \\
No. of double pan-cake coils & 10 \\
No. turns per double pancake & 208 \\
Total amount of superconductor & $4500 \mathrm{~m}$ \\
Full load current & $225 \mathrm{~A}$ \\
Maximum magnetic field at full current & $2.8 \mathrm{~T}$ \\
Inductance $^{\text {Operating temperature }}$ & $5.0 \mathrm{H}$ \\
\hline
\end{tabular}

${ }^{*}$ For the difference between widths of straight and end sections, see Section III.

\section{Coil Fabrication Methodology}

The use of multiple double pancake coils was chosen over a single layer wound coil since $\mathrm{MgB}_{2}$ wires are not yet produced in piece lengths long enough for winding the coil without joints. With double pancake coils, the joints between pieces appear in the low magnetic field region outside the coil. Furthermore, the use of double pancake coils makes it possible to remove or short-circuit malfunctioning parts.

Wet-winding was chosen over dry-winding to reduce the number of steps in the winding process. Also, whereas drywinding requires a glass-fiber fabric insulation or similar, wetwinding allows for the use of e.g. Kapton insulation or possibly, as described below, no dedicated electrical insulation at all. The main drawbacks of the wet-winding method are that the process needs to be carefully tuned to obtain the desired thickness of the epoxy layer and that the entire double pancake coil needs to be wound during the pot-life of the epoxy.

The electrical insulation between layers of the coil occupies space, reduces the radial thermal conductivity, and contributes to the cost (currently approximately $10 \%$ of the wire cost using a cost of $0.4 € / \mathrm{m}$ for the Kapton tape insulation considered). Hence, if the dedicated electrical insulation can be omitted, there may be significant cost savings and thermal

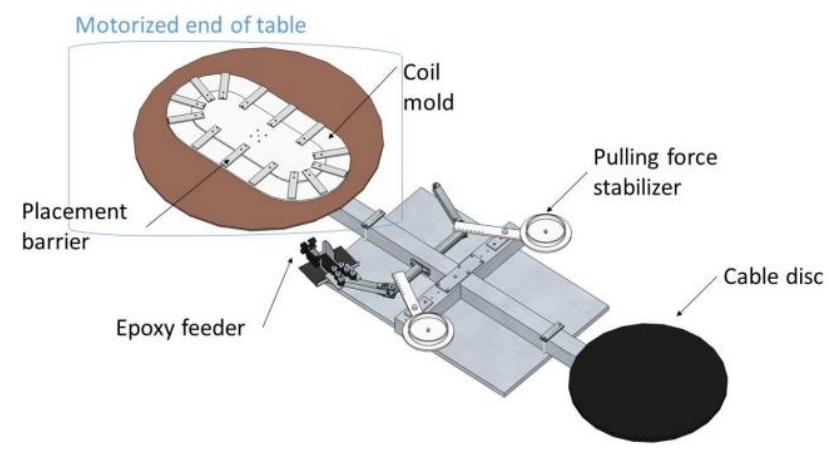

Fig. 1. Schematic drawing of winding table.

stability improvements. Although there have recently been growing interest of no-insulation coils [21]-[23], allowing direct metal-to-metal contact between turns, this may not be an option due to the long energizing times. Instead, the epoxy attached to the $\mathrm{MgB}_{2}$ wire during winding is used for electrical insulation between turns [24].

\section{COIL WINDING}

The double pancake coils were wound using a winding table schematically shown in Fig. 1. The spool with the conductor was placed to the right, and the racetrack-shaped bobbin on the winding table to the left. In between there were pulling force stabilizers to limit the tension of the wire in case of e.g. an abrupt stop. The winding of a double pancake coil starts at the midpoint of the conductor length. Hence, half of the conductor length was wound onto a spool, which were placed on top of the bobbin on the winding table. The lower layer of the double pancake was then wound by turning the motorized winding table. Between the cable disc and the winding table the conductor passed an epoxy feeder, filled with Stycast 2850, see Fig. 2. It is important in this step that enough epoxy is feed to the wire such that no section is left uninsulated, while not allowing excessive epoxy to attach to the wire. The latter is important for the straight section, where there practically is no inward force on the wire pushing epoxy upwards where it can be removed and hence, excessive epoxy tends to increase the coil width of the straight section. The wire passed through slits in plastic foam walls on its way in

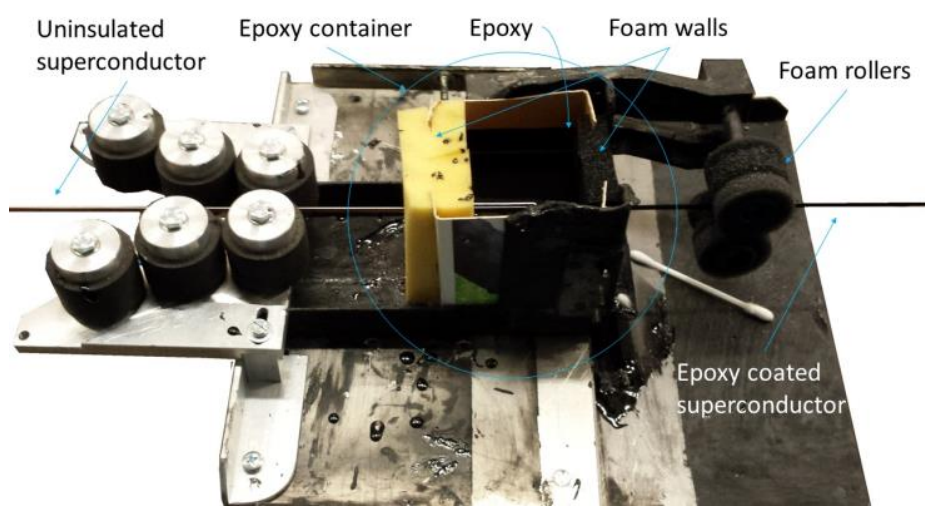

Fig. 2. Epoxy feeder. The wire enters from the left side and leaves the feeder to the right with a thin layer of epoxy applied. 
and out of the epoxy container, and a set of foam rollers adjusted the amount and equalized the thickness of the epoxy layer after passing the container. The pressure on the foam walls and rollers required some fine-tuning to obtain a thin and uniform epoxy layer on the conductor surfaces.

After the lower layer was wound (Fig. 3), the spool placed on top of the bobbin was moved to the other end of the winding table. The placement barriers were raised one conductor width and ten $0.5 \mathrm{~mm}$ thick and $10 \mathrm{~mm}$ wide epoxy spacers were put on the lower layer to assure that there would be no electrical contact between the two layers.

The winding procedure was repeated for the upper layer. The two wire ends were then cleaned and stretched. The weak points, where the conductor leaves the coil, were strengthened by adding a short piece of superconductor to each side of the wire.

During winding, the straight section was allowed to be slightly elliptically shaped to ease winding and to avoid excessive tension on the wire at the curvature change between the end section and the straight section. Three to four pieces of superconducting wires were placed in the small gap between the bobbin and the innermost wire on the straight section as armoring for the epoxy.

The winding speed was approximately $10 \mathrm{~m} / \mathrm{min}$ (lower for the first and last turns), and altogether all winding steps, including preparation and supplementary work, took approximately 8 hours for one double pancake.

The coil was cured at room temperature over night.

The width of the coil became $81 \mathrm{~mm}$ at end section, yielding an epoxy layer thickness of $0.08 \mathrm{~mm}$ between turns, which is less than the $0.15 \mathrm{~mm}$ anticipated if one would have used Kapton insulation between turns [20].

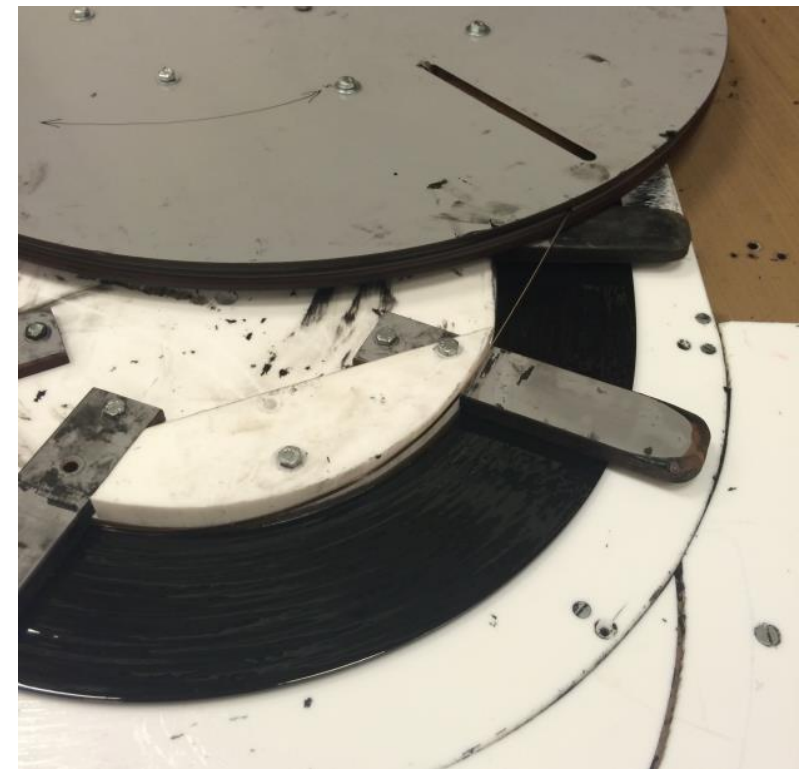

Fig. 3. Lower layer of a double pancake coil fully wound. The wire for the upper layer has been temporarily stored on the spool on top of the winding table while winding the lower layer.

\section{Coll Assembly}

\section{A. Stacking and Joining Double Pancakes}

The first double pancake coil was glued (with Stycast 2850) to the copper thermal interface, later to be used for testing of the coil. The remaining double pancake coils were then added one at a time with overnight curing of the epoxy in between the layers. To secure electrical insulation, $0.5 \mathrm{~mm}$ glass-fiber reinforced spacers were placed between the double pancake coils in the same manner as between the layers within a double pancake coil.

The wire ends of adjacent double pancake coils were soldered together, see Fig. 4. A solder with a melting point of $217^{\circ} \mathrm{C}$, sufficiently low not to interfere with the solder used between the nickel matrix and the copper strip of the wire, was applied to each of the ends. A specially designed soldering iron was used to melt the solder and provide only a thin layer (to avoid excessive joule heating in the joint) of solder in between the two wires. The soldering iron was equipped with two $100 \mathrm{~mm}$ long metal plates which heated the wires, and pressed them together with a spring system. In this way joints with less than $100 \mu \mathrm{m}$ thick layers of solder were made.

\section{B. Mechanical Support}

Whereas the superconductor itself is mechanically strong enough to handle the electromagnetic forces of a circular coil (and thereby the end section of the racetrack coil), the straight section needs mechanical support. A two-dimensional finite element calculation determined the force to be $110 \mathrm{kN} / \mathrm{m}$ for the straight section. This number is important for a full-scale (with a $3 \mathrm{~m}$ long straight section) coil. For the scaled coil, the contribution from the end section becomes significant, and a three-dimensional calculation is necessary, resulting in a total outward force of $86 \mathrm{kN}$ for the $0.5 \mathrm{~m}$ straight section.

The mechanical support, illustrated in Fig. 5, was designed and dimensioned using a simplified analysis with the aim of

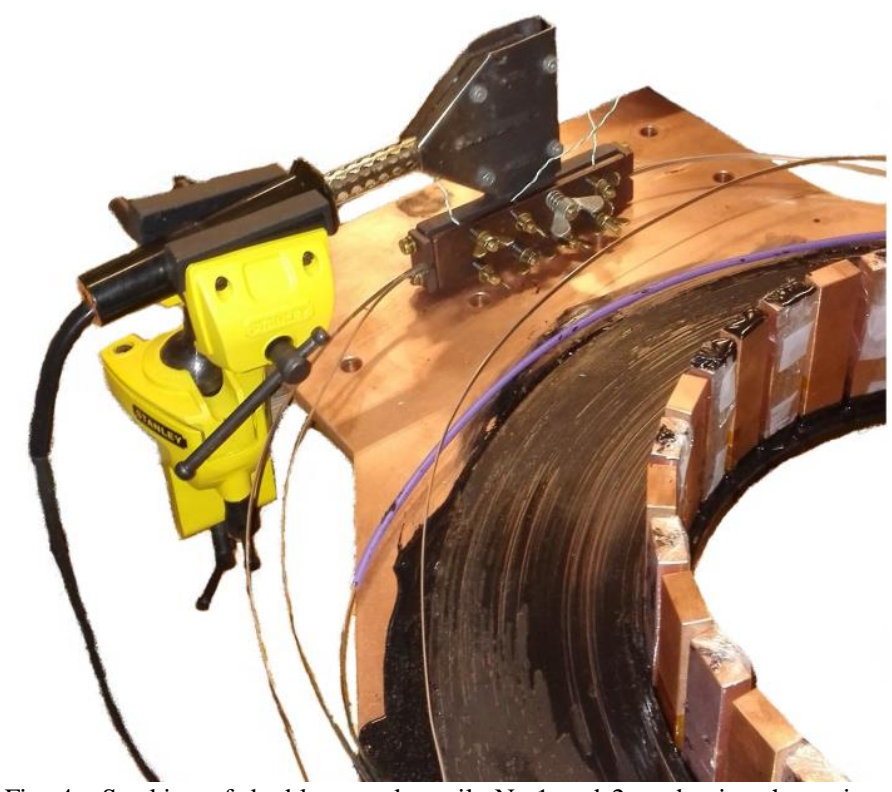

Fig. 4. Stacking of double pancake coils No.1 and 2, and using the spring system soldering iron to join the wire ends of the two double pancakes. 


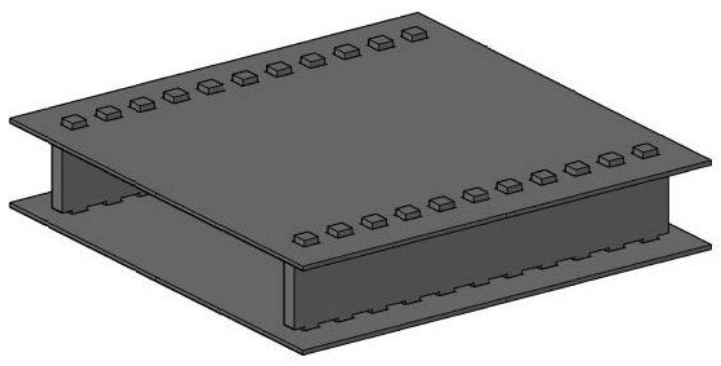

Fig. 5. Design of mechanical support.

keeping the deformations of the coil small. The fingers of two $20 \mathrm{~mm}$ thick stainless steel backplates fit into two $5 \mathrm{~mm}$ thick stainless steel plates crossing the opening of the coil. The solution with fingers was preferred over solutions with bolts or screws to avoid the use of different materials and to avoid weak points. Assuming that the outward force is acting directly on the mechanical support, it was found that the average stress in the $5 \mathrm{~mm}$ plate at full current was $22 \mathrm{MPa}$, with an elongation of $0.05 \mathrm{~mm}$. The $0.2 \%$ proof stress for the AISI type $316 \mathrm{~L}$ stainless steel used is approximately $210 \mathrm{MPa}$ [25], and although the stress is significantly higher at the corners of the holes (which should be made with a curvature), the safety margin is high. The deformation of the backplates at the center, assuming that the outward force is uniformly distributed over the backplate, is less than $0.02 \mathrm{~mm}$. With a total outward elongation of less than $0.1 \mathrm{~mm}$, the tensile strain of the $\mathrm{MgB}_{2}$ wire becomes of the order $10^{-5} \%$, far less than the allowed $0.1 \%$.

For the mechanical support to act uniformly on the coil, the surface of the coil at the interface with the support needs to be flat. Therefore, epoxy was added to the outer surface of the straight section of the coil to make it fit perfectly with the backplates of the support, see Fig. 6 .

\section{Full Coil}

The coil with the mechanical support is shown in Fig. 7 during mounting in a cryostat for later tests. The measured inductance, $5.0 \mathrm{H}$ (obtained at room temperature by measuring impedance at different frequencies), and the room temperature resistance determined by the copper strip and nickel matrix, $99.9 \Omega$ (evenly distributed between double pancake coils), showed that there were no major shorts between turns or pancakes, indicating that the epoxy layer had provided sufficient electrical insulation.

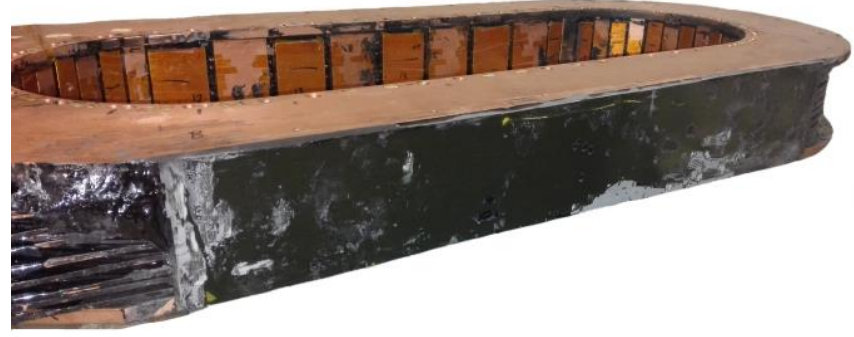

Fig. 6. Outer surface of straight section of the coil made flat to distribute the mechanical forces.

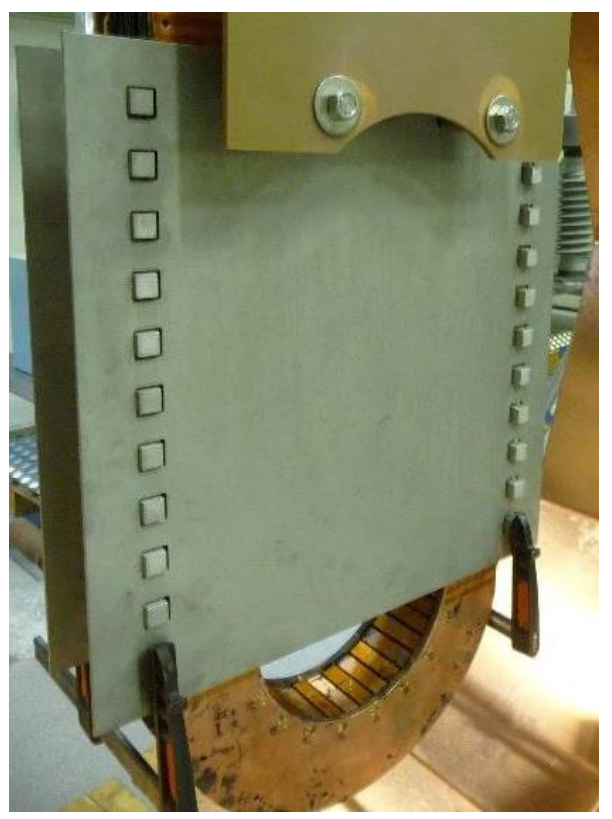

Fig. 7. Full coil with mechanical support during mounting in cryostat.

The coil is glued directly to the copper thermal interface plates and inner lamination, constituting a unit that can be directly connected to the cold head of a cooling machine. The next step is to insert the coil in a cryostat and prepare for testing. A forthcoming article will describe the tests, including the test set-up, and discuss the electromagnetic properties of the coil in detail.

\section{DISCUSSION}

Both dry-winding and wet-winding can be viable methods for winding large $\mathrm{MgB}_{2}$ coils for e.g. wind turbine generators. The dry-winding method as used in [19] yields the more defined coil dimensions since the turn-to-turn distance is given by the insulation thickness (and is not dependent on the epoxy layer thickness) and the subsequent vacuum impregnation can be performed in a mold.

The use of the wet-winding method may be motivated by the one-step winding process, which potentially can reduce manufacturing costs. A geometrically defined coil (as for drywinding) can be obtained by, as a second step, casting the entire coil in a mold. Also, for wet-winding it is possible to wind without dedicated electrical insulation, not before tested on $\mathrm{MgB}_{2}$ coils of this size. The absence of a Kapton insulation, as used in [13], results in a stiffer coil, avoiding the spongy effect [26], but leaving less soft material to take up any differences in thermal contraction between the materials or contractions of the epoxy during curing.

The mechanical support was made for test purposes and is heavily oversized. A more optimized support requires a more detailed analysis of the stresses in the cross-over plates near the holes for the backplate fingers.

The cost of the $\mathrm{MgB}_{2}$ wire for the coil was approximately $18 \mathrm{k} €$ (using $4 € / \mathrm{m}$ ), corresponding to $60 \mathrm{k} €$ for one full-scale pole at the present cost level. 


\section{CONCLUSIONS}

A scaled wet-wound $\mathrm{MgB}_{2}$ racetrack generator pole has been fabricated. The hands-on experience reported, derisks further efforts in coil winding for large $\mathrm{MgB}_{2}$ based wind turbine generators. The coil now enters the next phase with cool-down and electrical testing.

\section{REFERENCES}

[1] R. Fair, "Superconductivity for Large Scale Wind Turbines," DOE report DEEE0005143G, 2012.

[2] Y. Yang, S. Duan, Y. Ren, Y. Jiang, L. Feng, X. Zhang, H. Chai, M. Kuang, J. Wu, X. Yang and Y. Zhao, "Design and Development of a Cryogen-Free Superconducting Prototype Generator with YBCO Field Windings," IEEE Trans. Appl. Supercond. Vol. 26, No. 4, Art. No. 7370943, June 2016.

[3] Y. Liu, M. Noe, and M. Doppelbauer, "Feasibility Study of a Superconducting DC Direct-Drive Wind Generator," IEEE Trans. Appl. Supercond., vol. 26, No. 4, Art. No. 5203906, June 2016.

[4] A. B. Abrahamsen, N. Magnusson, B. B. Jensen and M. Runde, "Large superconducting wind turbine generators," Energy Procedia, vol. 24, pp. 60-67, 2012.

[5] S. Sanz, T. Arlaban, R. Manzanas, M. Tropeano, R. Funke, P. Kovác, Y. Yang, H. Neuman and B. Mondesert, "Superconducting light generator for large offshore wind turbines," J. Phys. Conf. Ser., vol. 507, Art. No. 032040, 2014.

[6] Y. Guan, Z. Q. Zhu, Z. Azar, A. S. Thomas, F. Vedreno-Santos, G.-J. Li and M. Odavic, "Comparison of Electromagnetic Performance of 10MW Superconducting Generators With Different Topologies for Offshore Direct-Drive Wind Turbines," IEEE Trans. Appl. Supercond., vol. 27, No. 7, Art. No. 5204211, October 2017.

[7] Y. Liu, J. Ou and M. Noe, "A Large-Scale Superconducting DC Wind Generator Considering Concentrated/Distributed Armature Winding," IEEE Trans. Appl. Supercond., vol. 27, No. 4, Art. No. 5200405, June 2017

[8] Y. Xu, N. Maki and M. Izumi, " Performance Comparison of 10-MW Wind Turbine Generators With HTS, Copper, and PM Excitation," IEEE Trans. Appl. Supercond., vol. 25, No. 6, Art. No. 5204006, December 2015.

[9] Y. Terao, M. Sekino and H. Ohsaki, " Electromagnetic Design of 10 MW Class Fully Superconducting Wind Turbine Generators," IEEE Trans. Appl. Supercond., vol. 22, No. 3, Art. No. 5201904, June 2012.

[10] I. Marino, A. Pujana, G. Sarmiento, S. Sanz, J. M. Merino, M. Tropeano, J. Sun and T. Canosa, "Lightweight $\mathrm{MgB}_{2}$ superconducting $10 \mathrm{MW}$ wind generator," Supercond. Sci. Technol. Vol. 29, Art. No. 024005, 2016.

[11] M. Modica, S. Angius, L. Bertora, D. Damiani, M. Marabotto, D. Nardelli, M. Perrella, M. Razeti and M. Tassisto, "Design, construction and tests of $\mathrm{MgB}_{2}$ coils for the development of a cryogen free magnet," IEEE Trans. Appl. Supercond., vol. 17, No. 2, pp. 2196-9, June 2007.

[12] S. Mine, M. Xu, S. Buresh, W. Stautner, C. Immer, E. T. Laskaris, K. Amm and G. Grasso, "Second Test Coil for the Development of a Compact $3 \mathrm{~T} \mathrm{MgB}_{2}$ Magnet," IEEE Trans. Appl. Supercond., vol. 23, No. 3, Art. No. 4601404, June 2013.

[13] F. Sætre, I. Hiltunen, M. Runde, N. Magnusson, J. Järvelä, J. Bjerkli and E. Engebrethsen, "Winding, cooling and initial testing of a $10 \mathrm{H}$ superconducting $\mathrm{MgB}_{2}$ coil for an induction heater," Supercond. Sci. Technol., vol. 24, Art. No. 035010, 2011.

[14] M Runde, A Stenvall, N Magnusson, G Grasso and R Mikkonen, " $\mathrm{MgB}_{2}$ coils for a DC superconducting induction heater," J. Phys.: Conf. Ser., vol. 97, Art. No. 012159, 2008.

[15] X. H. Li, X. J. Du, M. Qiu, Y. W. Ma and L. Y. Xiao, "Design and experimental demonstration of an $\mathrm{MgB}_{2}$ based 1.5 T MRI test magnet," Physica C, vol. 463-465, pp. 1338-1341, 2007.

[16] R. Pasquet, C. Berriaud, F. Forest, C. Hilaire, F. P. Juster, A. Porhiel, T. Schild, L. Scola and A. Taleb, "Design and Test of a Small React-and-Wind $\mathrm{MgB}_{2}$ Double Pancake," IEEE Trans. Appl. Supercond. vol. 25, No. 3, Art. No. 4603605, June 2015.

[17] H. S. Kim, C. Kovacs, M. Rindfleisch, J. Yue, D. Doll, M. Tomsic, M. D. Sumption, and E. W. Collings, "Demonstration of a Conduction Cooled React and Wind $\mathrm{MgB}_{2}$ Coil Segment for MRI Applications,"
IEEE Trans. Appl. Supercond. Vol. 26, No. 4, Art. No. 4400305, June 2016

[18] C. Hori, R. Nakagawa, Y. Imamura and H. Tanaka, "Development of a Test Conduction-Cooled $\mathrm{MgB}_{2}$ Coil," IEEE Trans. Appl. Supercond., vol. 26, No. 4, Art. No. 4901004, June 2016

[19] G. Sarmiento, S. Sanz, A. Pujana, J. M. Merino, I. Marino, M. Tropeano, D. Nardelli and G. Grasso, "Design and Testing of Real-Scale $\mathrm{MgB}_{2}$ Coils for Suprapower 10-MW Wind Generators," IEEE Trans. Appl. Supercond., vol. 26, No. 3, Art. No. 7397945, June 2016.

[20] A. B. Abrahamsen, N. Magnusson, B. B. Jensen, D. Liu and H. Polinder, "Design of an $\mathrm{MgB}_{2}$ race track coil for a wind generator pole demonstration," J. Phys. Conf. Ser., vol. 507, Art. No. 032001, 2014.

[21] O. J. Kwon, K. L Kim, Y. H. Choi, H. J. Shin, S. Hahn, Y. Iwasa and H. G. Lee, "Effects of turn-to-turn compactness in the straight sections of HTS racetrack coils on thermal and electrical characteristics," Supercond. Sci. Technol. Vol. 26, Art. No. 085025, 2013.

[22] H. Park, A. Kim, S. Kim, M. Park, K. Kim and T. Park, "Mechanical and electric characteristics of vacuum impregnated no-insulation HTS coil," Physica C vol. 504, pp. 138-143, 2014.

[23] S. Hahn, J. Song, Y. Kim, T. Lecrevisse, Y. Chu, J. Voccio, J. Bascunan and Y. Iwasa, "Construction and Test of 7-T/68-mm Cold-Bore Multiwidth No-Insulation GdBCO Magnet," IEEE Trans. Appl. Supercond., vol. 25, No. 3, Art. No. 4600405, June 2015.

[24] N. Magnusson, J. C. Eliassen, A. B. Abrahamsen, A. Nysveen, J. Bjerkli, M. Runde and P. King, "Design aspects on winding of an $\mathrm{MgB}_{2}$ superconducting generator coil," Energy Procedia, vol. 80, pp. 56-62, 2015

[25] Nickel Development Institute, "Materials for Cryogenic Service: Engineering Properties of Austenitic Stainless Steels," NiDI publication No. 4368,1974

[26] M. N. Wilson, Superconducting magnets. New York: Oxford University Press, p. 46, 1983. 